\title{
The virus doesn't go on vacation
}

\author{
Giorgina B. Piccoli ${ }^{1,2}$
}

Published online: 5 August 2021

(c) Italian Society of Nephrology 2021

When I was a teenager, and the era of connections and smartphones was still to come, we used to go to the seaside for summer vacation because it was good for our health. My mother filled a suitcase with books because it was good for our brains, making sure to include Russian classics, that, even in paperback edition, were as heavy as bricks.

My grandmother, quite wisely, integrated our beach activities with "gialli", as the weekly mystery books were called in Italy, due to their yellow cover. The summer edition was always called some variation of "death-crime-murderers do not go on vacation".

This is what popped into my mind while preparing this summer edition of JN, that gathers first of all several series, original papers, commentaries and cases clearly showing that Sars-CoV-19 is not ready for vacation.

When I play with my three-month-old goddaughter, conceived and born during the pandemic, I wonder what we'll tell her about this period, and indeed what we have learned.

One year ago, we collected the personal experiences of some young physicians, with various backgrounds and roles [1]. Reading it one year later, we realize that we were probably more psychologically prepared for a heroic battle rather than for an exhausting war. Lessons are however there: in this issue, we reflect upon the fact that the virus taught us that we may be more skilled in the fight against hospitalacquired infections than we thought; we gather new data on the role of electrolytes in critical conditions, we try to better understand the flares of immunologic diseases linked to the viral disease or to the vaccine to gain new insights into the pathogenesis of the diseases we usually treat, and we start reflecting on the overall vaccine policy in our fragile patients.
We also reflect on the simple things we have at least temporarily lost: our patients used to eat during the dialysis sessions, and, while controversial, mainly because of the fear of favoring or inducing hypotension, this habit could be very important in the fight against protein energy wasting. Moreover, wise combinations of food, or custom-made ones, such as the muffins proposed in this issue, combine efficacy with low cost and a friendly, non pharmacological attitude... Indeed, the old adage is always true: loss makes us understand what we had. Or to quote a famous song "..you don't know what you've got till it's gone"-Joni Mitchell.

Along this same line, we chose for this issue several papers on frailty, exercise, assessment of the muscle mass: we need to be more inclusive, probably not only in our evaluations but also in our interventions: the dialysis ward could be a setting of integrated care, with nutritional support as well as tailored exercise. Social isolation has also provided a means for reflecting on the potential for exploiting the opportunities to "go out", including for care.

This desire to turn the experience of the pandemic into an improvement of our daily practice may give us an even greater appreciation of two great lessons of one of our masters, prof. Ponticelli, on rheumatologic diseases that are of particular interest for nephrologists, as well as a variety of research papers and reviews on different aspects of our discipline.

Bearing in mind the idea that if the restless virus does not go on vacation, we probably might, at least for a short time, maybe with shorter trips...

Have a nice rest, my friends, and, if you want to remain nephrologists even at the beach, play with the interesting images and teaching cases, as an occasional alternative to Sudoku on a sunny day.
Giorgina B. Piccoli

gbpiccoli@yahoo.it

1 Centre Hospitalier Le Mans, Le Mans, France

2 Dipartimento di Scienze Cliniche e Biologiche, University of Torino, Turin, Italy 


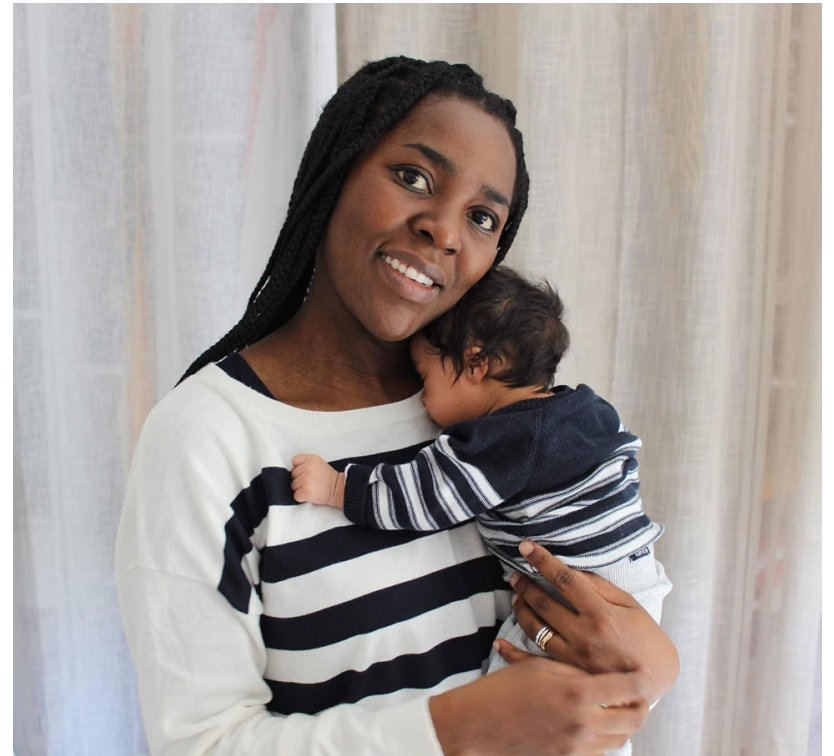

This issue is dedicated to my goddaughter Siha and to all the children of the pandemic.

\section{Declarations}

Conflict of interest The authors declare that they have no conflict of interest.

Ethical approval This article does not contain any studies with human or animal subjects performed by any of the authors.

\section{Reference}

1. ICONA members, Gambaro G, Piccoli GB (2020) Nothing will ever be as before. Reflections on the COVID-19 epidemics by nephrologists in eleven countries. J Nephrol 33:633-637. https:// doi.org/10.1007/s40620-020-00756-7

Publisher's Note Springer Nature remains neutral with regard to jurisdictional claims in published maps and institutional affiliations. 